\title{
Odorant receptor genes are expressed in olfactory neuroblastoma
}

D.C. Gonzalez-Kristeller ${ }^{1}$, L.M. Gutiyama ${ }^{1}$, A.H. Campos ${ }^{2}$, F.A. Soares ${ }^{2}$, H. Brentani ${ }^{3}$ and B. Malnic ${ }^{1}$

${ }^{1}$ Departamento de Bioquímica, Instituto de Química, Universidade de São Paulo, São Paulo, SP, Brasil

${ }^{2}$ Departamento de Anatomia Patológica, Hospital A.C. Camargo,

Fundação Antônio Prudente, São Paulo, SP, Brasil

${ }^{3}$ Departamento de Psiquiatria, Faculdade de Medicina,

Universidade de São Paulo, São Paulo, SP, Brasil

Corresponding author: B. Malnic

E-mail: bmalnic@iq.usp.br

Genet. Mol. Res. 12 (3): 3479-3487 (2013)

Received January 20, 2013

Accepted May 29, 2013

Published September 10, 2013

DOI http://dx.doi.org/10.4238/2013.September.10.4

\begin{abstract}
Olfactory neuroblastoma (ONB) is a malignant tumor found in the human nasal cavity. These tumors are rare and poorly characterized at the molecular level. In this study, we asked whether olfactory-specific genes are expressed in ONBs by using reversetranscriptase-polymerase chain reaction. We found that the olfactory marker protein and the $R I C-8 B$ genes, which are specifically expressed in mature olfactory neurons, are expressed in ONBs. Importantly, we also found that ONBs express a large variety of odorant receptor genes, representative of different odorant receptor gene subfamilies. Our results show that the ONBs express genes that are normally expressed in mature olfactory neurons and indicate that they are derived from progenitor or immature cells in the olfactory epithelium and not from a clonal expansion of a single or few mature olfactory neurons.
\end{abstract}

Key words: Olfactory neuroblastoma; Odorant receptors; $R I C-8 B$ gene; Olfactory marker protein; Esthesioneuroblastoma 


\section{INTRODUCTION}

Esthesioneuroblastoma or olfactory neuroblastoma (ONB) is a rare and aggressive tumor that usually occurs in the upper nasal cavity. This type of tumor accounts for only $6 \%$ of the tumors found in the nasal cavity and paranasal sinuses (Svane-Knudsen et al., 1998; Faragalla and Weinreb, 2009). It was first described as 'olfactory esthesioneuroepithelioma' in 1924 by Berger et al. ONBs are usually large tumors that may fill the whole nasal cavity and although it is believed that ONBs are derived from the olfactory epithelium, its tissue of origin remains uncertain (Dulguerov et al., 2001). Because ONBs histologically resemble other types of tumors that occur in the sinonasal tract, they cannot be easily distinguished (Faragalla and Weinreb, 2009; Thompson, 2009). Therefore, the accurate identification of ONBs should contribute to the prognosis and treatment of these tumors.

Due to the rarity of this type of tumor, very few studies have been conducted to date on the molecular characterization of ONBs. A number of neuronal markers, such as neuron-specific enolase, synaptophysin, chromogranin, and others, have been detected in ONBs by immunohistochemical analysis, indicating that the tumor is derived from neuronal tissue (Faragalla and Weinreb, 2009). More direct evidence that ONBs are derived from olfactory sensory neurons came from a study that showed that the human Achaete-scute 1 gene, known to be involved in the differentiation of olfactory neurons, is expressed in ONBs (Carney et al., 1995) and that olfactory-specific signal transduction proteins, such as Gaolf, adenylyl cyclase III, and cyclic-nucleotide channel A2 (Firestein, 2001), are present in ONBs (Matayoshi and Otaki, 2011). The comparison of genomes from ONBs and corresponding normal tissues by whole genome sequencing should also contribute to the molecular characterization of the mutations involved in the generation of these tumors (Weiss et al., 2012). In this study, we analyzed 2 samples of ONBs for the expression of olfactory-specific genes that are normally expressed in mature olfactory neurons.

\section{MATERIAL AND METHODS}

\section{Tissue samples}

Two olfactory neuroblastoma samples, denominated NF7T and NF9T, were obtained from 2 different individuals from the nasal cavity and maxilla, respectively. Samples were provided by the A.C. Camargo Hospital Biobank (Campos, 2012). Experiments were performed in accordance with the policies of the Research Ethics Committee of the A.C. Camargo Hospital. This committee ensures compliance with existing ethical principles in the Brazilian legislation.

\section{RNA extraction and cDNA synthesis}

Total RNA extraction from the ONB samples was carried out using the RNeasy ${ }^{\circledR}$ Mini Kit (Qiagen, USA). RNA samples from normal human tissues were obtained from a panel of total RNA (Clontech, USA). cDNA synthesis was performed as previously described (Von Dannecker et al., 2005) using oligo dT primers. 


\section{Polymerase chain reaction (PCR)}

Human $R I C-8 B$ was amplified using a pair of primers specific to human $R I C-8 B$ located in exons 8 (forward primer) and 10 (reverse primer) to exclude the possibility of contamination with genomic DNA. Human $O M P$ was amplified using a pair of primers that amplify the region of the coding sequence between nucleotides 32 and 476. PCR was performed as previously described (Von Dannecker et al., 2005), except that $2.5 \mu \mathrm{L}$ cDNA was used in the reactions. Reactions were heated to $95^{\circ} \mathrm{C}$ for $2 \mathrm{~min}$ and then subjected to 20 thermal cycles of $95^{\circ} \mathrm{C}$ for $45 \mathrm{~s}, 55^{\circ} \mathrm{C}$ for $45 \mathrm{~s}$, and $72^{\circ} \mathrm{C}$ for $1 \mathrm{~min}$, with a final incubation of $72^{\circ} \mathrm{C}$ for $10 \mathrm{~min}$. As a control, we amplified human $G A P D H$.

For the amplification of human odorant receptor (OR) transcripts, the PCR solution contained $0.5 \mathrm{mM}$ of each degenerate primer, $0.2 \mathrm{mM}$ of each dNTP, 1X Taq DNA polymerase buffer, $1 \mathrm{U}$ Taq DNA polymerase (Invitrogen Life Technologies, USA), $1.5 \mathrm{mM} \mathrm{MgCl}$, and $2.5 \mu \mathrm{L}$ synthesized cDNAs in a final volume of $50 \mu \mathrm{L}$. The thermocycler (Perkin Elmer, USA) was programmed as follows: initial denaturation for $2 \mathrm{~min}$ at $96^{\circ} \mathrm{C}$, followed by 25 cycles of $1 \mathrm{~min}$ at $96^{\circ} \mathrm{C}, 3 \mathrm{~min}$ at $40^{\circ} \mathrm{C}$, and $3 \mathrm{~min}$ at $72^{\circ} \mathrm{C}$, followed by a final step of $10 \mathrm{~min}$ at $72^{\circ} \mathrm{C}$. The sequences of the primers used are:

Human RIC-8B, forward: 5'-TACTCAGAGGATGAGGACACACAC-3', reverse: 5'-GTCTAACTGCAGCTCTGTATGAATG-3'; human $G A P D H$, forward: 5'-CTGCACCAC CAACTGCTTA-3', reverse: 5'-CATGACGGCAGGTCAGGTC-3'; human OMP, forward: 5'-TGGACATGCCGCTGGTCCTG-3', reverse: 5'-CCACGGAGGCCTTGAGGTTG-3'; P26, (forward): 5'-CITA(CT)GA(CT)CGITA(CT)GTIGCIATITG-3' and P27 (reverse): 5'-ACIACI GAIAG(GA)TGIGAI(GC)C(GA)CAIGT-3'.

\section{DNA sequencing}

The PCR products obtained by using the degenerate primers were gel purified, cloned into the pCRII vector (Invitrogen), and transformed into competent DH5 $\alpha$ Escherichia coli cells (Invitrogen Life Technologies). DNA sequencing was performed using an ABI PRISM ${ }^{\mathrm{TM}}$ 3100 device (Applied Biosystems, USA). The sequencing reaction consisted of $2 \mu \mathrm{L}$ Big Dye terminator mix (Perkin Elmer), 100-200 ng DNA, 9.6 pmol of each oligonucleotide, $200 \mathrm{mM}$ Tris- $\mathrm{HCl}, \mathrm{pH} 9.0$, and $5 \mathrm{mM} \mathrm{MgCl}_{2}$ in a final volume of $15 \mu \mathrm{L}$. The reaction was incubated for 2 min at $95^{\circ} \mathrm{C}$, followed by 35 cycles of $45 \mathrm{~s}$ at $96^{\circ} \mathrm{C}, 30 \mathrm{~s}$ at $50^{\circ} \mathrm{C}$, and $4 \mathrm{~min}$ at $60^{\circ} \mathrm{C}$. After the reaction was completed, samples were precipitated with $100 \%$ ethanol and $1 \mathrm{mg} / \mathrm{mL}$ glycogen, rinsed with $70 \%(\mathrm{v} / \mathrm{v})$ ethanol, suspended in $20 \mu \mathrm{L}$ formamide, denatured at $94^{\circ} \mathrm{C}$ for $5 \mathrm{~min}$, and subjected to automatic sequencing.

\section{Phylogenetic analysis}

OR amino acid sequences were aligned and used to generate a rooted phylogenetic tree with branch length (UPGMA) by using Clustalw (http://www.genome.jp/tools/clustalw/).

\section{RESULTS}

Two ONB samples, denominated NF7T and NF9T, were analyzed in this study. His- 
tological analysis demonstrated that they were entirely (100\%) composed of tumor tissue, as shown in Figure 1.
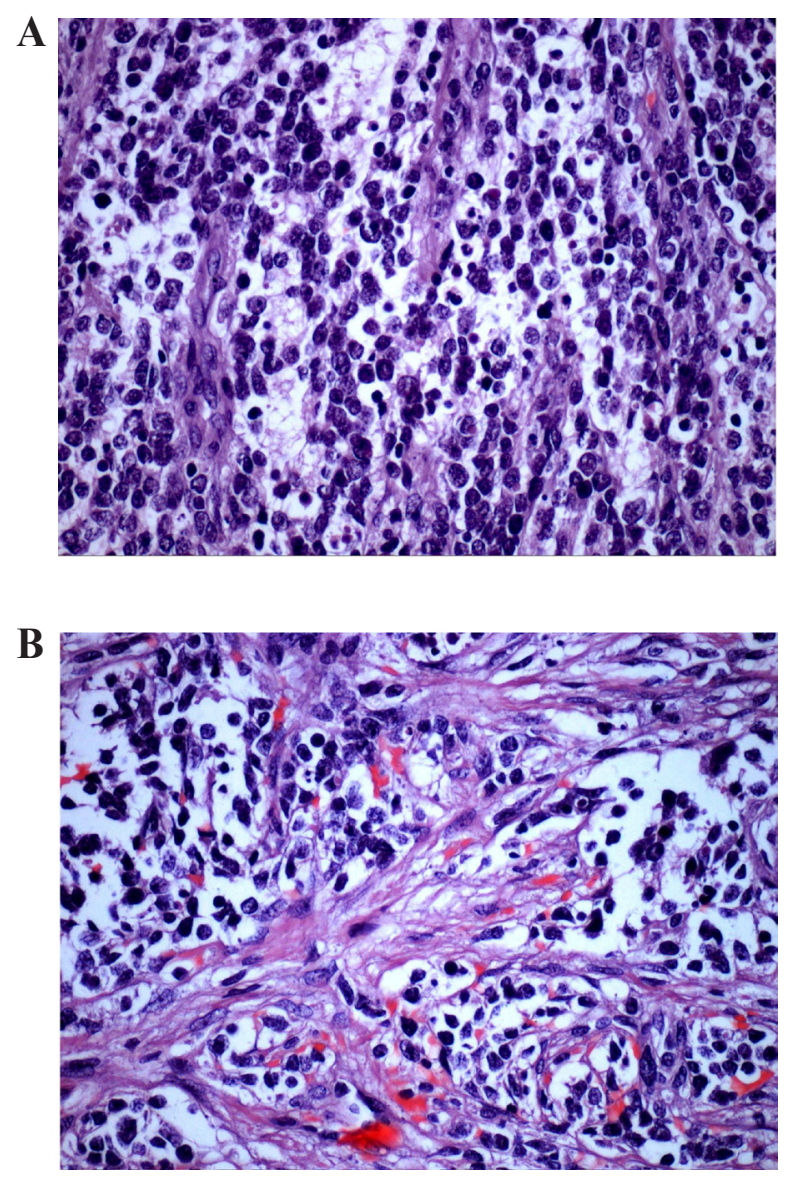

Figure 1. Histological analysis of olfactory neuroblastoma. Sections cut through the NF9T sample were stained with hematoxylin and eosin and analyzed under an Olympus BX43 microscope (magnification 400X). The tumors are composed of cells with round to oval nuclei and scanty cytoplasm (A), often forming clusters separated by a fibrovascular stroma (B). A fibrillary background is evident

We performed reverse transcriptase (RT)-PCR experiments in order to determine the expression of 2 olfactory-specific genes, $O M P$ and $R I C-8 B . O M P$ is expressed specifically in mature olfactory neurons, both in the main and accessory olfactory system, and is therefore commonly used as a marker for this type of cell (Farbman and Margolis, 1980). RIC-8B is a guanine nucleotide exchange factor that is predominantly expressed in mature olfactory neurons, only in the main olfactory system (Von Dannecker et al., 2005; Kerr et al., 2008; Chan et al., 2011). In order to detect the expression of the $R I C-8 B$ gene, we used a pair of primers complementary to regions that flank the 9th exon of the gene (Figure 2A). By using these primers we were able to identify the full-length $R I C-8 B$ transcript, and also the alternatively spliced transcript, which 
lacks exon 9 (Von Dannecker et al., 2005). We have previously shown that both transcripts (denominated $R I C-8 B$ and $R I C-8 B \triangle 9$ ) are present in the mouse olfactory epithelium at equivalent levels (Von Dannecker et al., 2005). As shown in Figure 2B, after 20 PCR cycles, we could detect $R I C-8 B$ gene expression only in the 2 ONB samples, and not in 9 other normal human tissues. Under the conditions that we used, the NF9T sample showed stronger expression of the RIC- $8 B$ gene than the NF7T sample. Contrary to what is observed in the mouse olfactory epithelium, in the ONB samples, the RIC- $8 B \triangle 9$ transcript was more abundant than the full-length $R I C-8 B$ transcript (Figure $2 \mathrm{~B}$ ). Like for $R I C-8 B$ gene, the expression of the $O M P$ gene was also observed only in the ONB samples, and not in the other tissues (Figure 2B). These results show that the olfactory-specific genes $O M P$ and $R I C-8 B$ are expressed at considerably high levels in the ONBs, since the transcripts can be detected after only 20 PCR cycles.

A

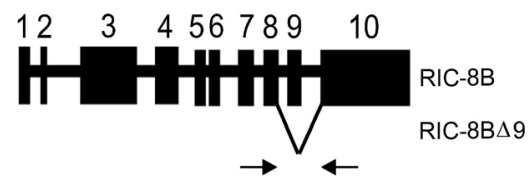

B

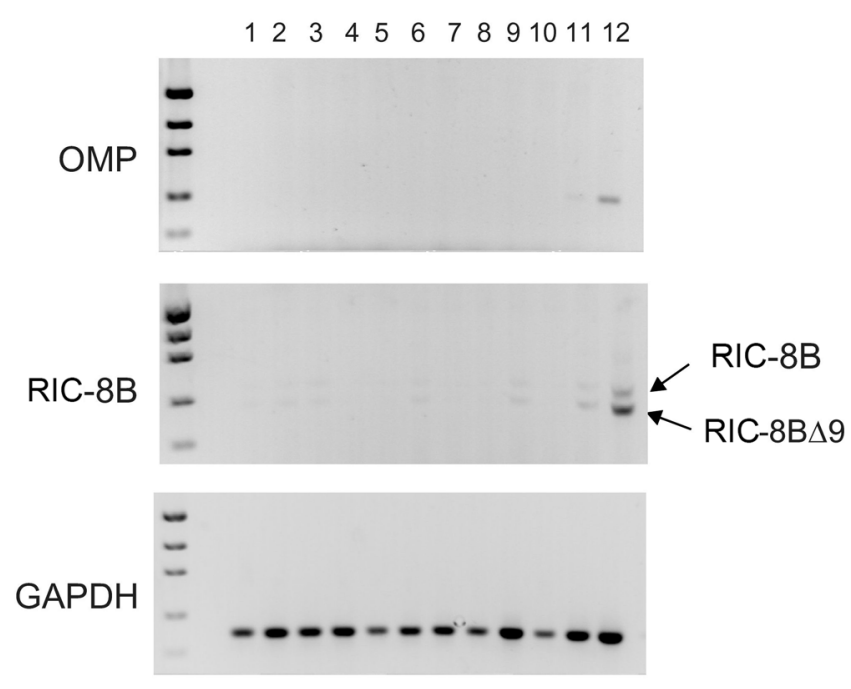

Figure 2. Expression of the $O M P$ and $R I C-8 B$ genes in different human tissues and in ONBs. cDNAs synthesized from different tissues were used to amplify the $O M P$ and $R I C-8 B$ transcripts. A. Schematic representation of the $R I C-8 B$ gene. The alternatively spliced version $R I C-8 B \Delta 9$ does not contain exon 9 , as indicated. The regions matching the primers used in the PCR experiments are indicated by arrows. B. RT-PCR was conducted to amplify $O M P, R I C-8 B$, and $G A P D H$ from the following tissues: lane $1=$ brain; lane $2=$ thymus; lane 3 = fetal brain; lane 4 $=$ heart; lane $5=$ kidney; lane $6=$ testis; lane $7=$ fetal liver; lane $8=$ lung; lane $9=$ skeletal muscle; lane $10=$ liver; lane $11=\mathrm{NF} 7 \mathrm{~T}$; lane $12=\mathrm{NF9T}$. The PCR product sizes expected for RIC-8B (413 bp) and RIC-8B 19 (371 bp) are indicated. The expected size for OMP is $446 \mathrm{bp}$. Size markers are 2000, 1200, 800, 400, and $200 \mathrm{bp}$. 
ORs are expressed specifically in the olfactory neurons of the nose, and are responsible for odorant recognition (Buck and Axel, 1991). Humans have approximately 400 intact OR genes, which constitute one of the largest gene families in the human genome (Malnic et al., 2004; Nei et al., 2008). We next checked whether the OR genes were also expressed in the ONBs. In order to be able to identify a large number of ORs, we used degenerate primers that hybridize to the majority of OR genes (Figure 3A) (Malnic et al., 1999; Michaloski et al., 2006). By using these primers, we were able to amplify a PCR product showing the expected size $(\sim 390 \mathrm{bp})$ from the ONB samples (Figure $3 \mathrm{~B})$. No amplification was obtained from the other tissues that were analyzed (Figure $3 \mathrm{~B}$ ). As shown for the RIC- $8 B$ and $O M P$ genes (Figure 2), the NF9T sample showed stronger expression of the OR genes when compared to the NF7T sample. These results could be due to the intrinsic heterogeneity of these 2 ONB samples, or also due to the low number of PCR cycles that were used in the experiments.
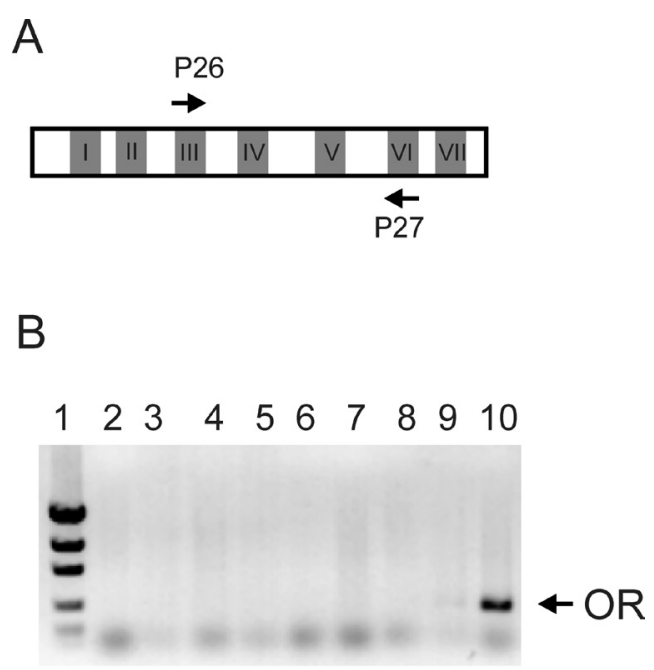

Figure 3. Expression of odorant receptor (OR) genes in different human tissues and in olfactory neuroblastomas. A. Schematic representation of an OR-coding region showing the 7 transmembrane regions (I-VII) and the regions matched by the P26 and P27 degenerate primers. B. Agarose gel (1.0\%) stained with ethidium bromide showing the RT-PCR products obtained by using the P26 and P27 degenerate primers from the following tissues: lane $2=$ liver; lane 3 = thymus; lane $4=$ fetal brain; lane $5=$ heart; lane $6=$ kidney; lane $7=$ testis; lane $8=$ skeletal muscle; lane $9=$ NF7T; lane $10=$ NF9T. Lane $1=$ molecular size markers: 2000, 1200, 800, 400, and $200 \mathrm{bp}$. The arrow indicates the PCR product with the expected size ( $\sim 390 \mathrm{bp})$.

The bands showing the expected molecular size were purified from the gel and cloned. Ninety-six individual clones were sequenced and sequence analysis indicated that the majority of the clones corresponded to OR genes. Overall, the sequences corresponded to 27 different OR genes. We next asked whether ONBs express a specific group of OR genes. In order to address this question we prepared a phylogenetic tree using the amino acid sequences of the complete repertoire of human OR genes (403 genes), and the localization of the OR genes that were expressed in the ONBs was determined. As shown in Figure 4, the OR sequences that we identified are not concentrated in a few branches, but are spread throughout the human OR phylogenetic tree, indicating that ONBs express a random sample of human OR genes. 


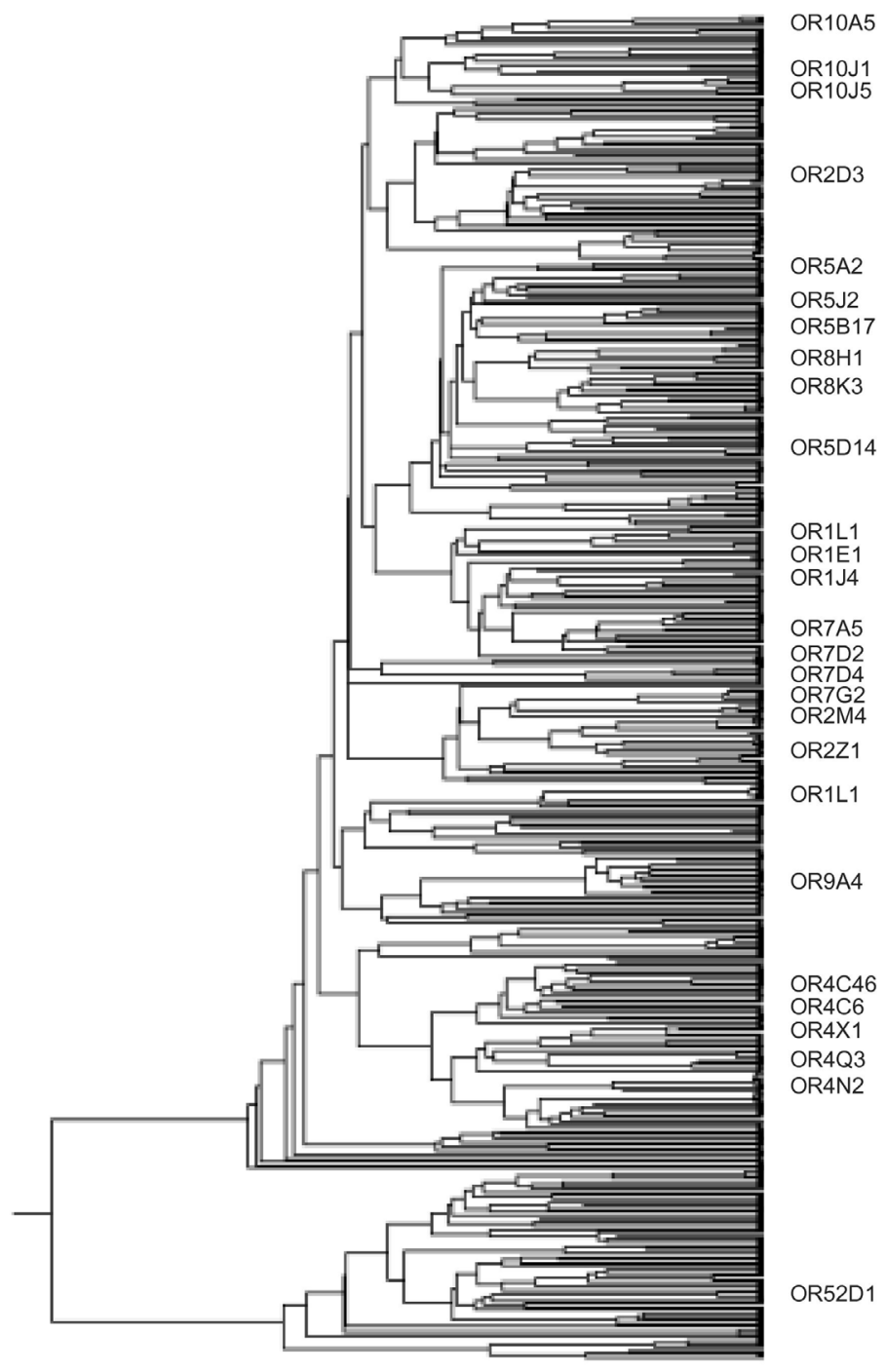

Figure 4. Phylogenetic tree of the human odorant receptors (ORs). A phylogenetic tree was prepared by using the amino acid sequences of 403 human OR genes. The OR genes expressed in the ONB are indicated at the right side of the tree.

\section{DISCUSSION}

In this research, we asked whether ONBs express olfactory-specific genes. Our results show that the 2 samples of ONBs that we analyzed in this study express genes, such as $O M P$, $R I C-8 B$, and OR genes, that are specifically expressed in mature olfactory neurons. Except for in a few cases (Zhang et al., 2004), these genes are not expressed in other tissues, and therefore can be considered as specific markers for olfactory neurons. Because histological analysis of the samples showed that they are entirely composed of tumor cells, our results indicate that 
the ONBs express these olfactory-specific genes and must therefore be derived from olfactory neurons.

In a previous study, immunohistochemistry was used to analyze the expression of $O M P$ and other olfactory-specific proteins in ONB (Matayoshi and Otaki, 2011). In that study, OMP expression was not detected, while other olfactory-specific proteins, such as Goolf, ACIII, and CNGCA2, which are normally expressed in mature olfactory neurons, were detected. Another study used RT-PCR to determine $O M P$ expression status in ONBs, and also failed to detect expression of this gene (Carney et al., 1995). The lack of detection of the OMP protein or mRNA could be due to a singularity of the ONB samples that were analyzed in these studies. In contrast to these results, our findings show that the $O M P$ gene is expressed in ONBs, together with other mature olfactory neuron-specific genes, such as $R I C-8 B$ and OR genes. The analysis of a larger number of ONB samples in the future should verify these observations.

We show here for the first time that ONBs express OR genes. Using degenerate primers complementary to the majority of the OR genes, we were able to analyze whether a large number of OR genes are expressed in ONBs. We amplified cDNAs corresponding to 27 different OR genes. We cannot exclude the possibility that additional genes are expressed in the ONBs that were not detected by our method (for example OR genes, which are expressed at lower levels). The OR genes that we detected belong to different subfamilies of the human OR gene family, indicating that a random and large variety of OR genes are expressed in the ONB. Interestingly, a previous study on ONBs showed that olfactory neuroblastoma cells are able to respond specifically to odorants (Gomez et al., 1996), indicating that the ORs expressed in this tumor are functional.

Mature olfactory neurons express a single OR gene allele from a large family of genes (Chess et al., 1994; Malnic et al., 1999). The fact that a large number of OR genes are expressed in the ONBs, instead of a single OR gene or just a few OR genes, also indicates that the ONBs are derived from progenitor cells or immature neurons in the olfactory epithelium, as previously observed (Carney et al., 1995), and not from a clonal expansion of a single or few mature olfactory neurons expressing any given OR gene.

It has been previously suggested that ONB cells could be used in order to study the different aspects of olfactory function (Gomez et al., 1996). It is well known, for example, that heterologous functional expression of OR genes is difficult to achieve, and requires coexpression with accessory proteins (Malnic, 2007; Zhuang and Matsunami, 2007). ONB cells could be used to study the odorant specificities of the different ORs that they express. Our results, together with those of other groups, show that ONBs express the olfactory genes that are usually expressed in mature olfactory neurons, indicating that they could be useful tools for studying olfactory function. In addition, if ONB cell lines expressing a single OR gene could be established, they would be useful to study the mechanisms of OR gene regulation.

In summary, our results provide tools that can be used for the accurate and early diagnosis of ONBs, and therefore should contribute to the understanding and appropriate management of this type of tumor. In addition, they indicate that the establishment of cell lines derived from ONBs could be useful for the study of the different aspects of olfactory function.

\section{ACKNOWLEDGMENTS}

We would like to thank Luci Navarro for help with the DNA sequencing. Research supported by grants from FAPESP and CNPq. 


\section{REFERENCES}

Berger L, Luc R and Richard D (1924). L'esthesioneuroepitheliome olfactif. Bull. Assoc. Franç. Etude Cancer 13: 410421.

Buck L and Axel R (1991). A novel multigene family may encode odorant receptors: a molecular basis for odor recognition. Cell 65: 175-187.

Campos AHJFM, Silva AA, Mota LDC, Olivieri ER, et al. (2012). The value of a tumor bank in the development of cancer research in Brazil: 13 years of experience at the A C Camargo Hospital. Biopreservation and Biobanking 10: 168-173.

Carney ME, O'Reilly RC, Sholevar B, Buiakova OI, et al. (1995). Expression of the human Achaete-scute 1 gene in olfactory neuroblastoma (esthesioneuroblastoma). J. Neurooncol. 26: 35-43.

Chan P, Gabay M, Wright FA and Tall GG (2011). Ric-8B is a GTP-dependent G protein alphas guanine nucleotide exchange factor. J. Biol. Chem. 286: 19932-19942.

Chess A, Simon I, Cedar H and Axel R (1994). Allelic inactivation regulates olfactory receptor gene expression. Cell 78: 823-834.

Dulguerov P, Allal AS and Calcaterra TC (2001). Esthesioneuroblastoma: a meta-analysis and review. Lancet Oncol. 2: 683-690.

Faragalla H and Weinreb I (2009). Olfactory neuroblastoma: a review and update. Adv. Anat. Pathol. 16: 322-331.

Farbman AI and Margolis FL (1980). Olfactory marker protein during ontogeny: immunohistochemical localization. Dev. Biol. 74: 205-215.

Firestein S (2001). How the olfactory system makes sense of scents. Nature 413: 211-218.

Gomez G, Restrepo D, Rawson N, Lowry LD, et al. (1996). Induction of differentiation of human olfactory neuroblastoma cells into odorant-responsive cells. Neuroscience 74: 567-577.

Kerr DS, Von Dannecker LEC, Davalos M, Michaloski JS, et al. (2008). Ric-8B interacts with $\mathrm{Ga}_{\text {olf }}$ and $\mathrm{Gg}_{13}$ and colocalizes with $\mathrm{Ga}_{\mathrm{olf}}, \mathrm{Gb}_{1}$ and $\mathrm{Gg}_{13}$ in the cilia of olfactory sensory neurons. Mol. Cell. Neurosci. 38: 341-348.

Malnic B (2007). Searching for the ligands of odorant receptors. Mol. Neurobiol. 35: 175-181.

Malnic B, Hirono J, Sato T and Buck LB (1999). Combinatorial receptor codes for odors. Cell 96: 713-723.

Malnic B, Godfrey PA and Buck LB (2004). The human olfactory receptor gene family. Proc. Natl. Acad. Sci. U. S. A. 101: 2584-2589.

Matayoshi R and Otaki JM (2011). Immunohistochemical detection of olfactory-specific sensory transduction proteins in olfactory neuroblastoma. Neurosci. Res. 69: 258-262.

Michaloski JS, Galante PA and Malnic B (2006). Identification of potential regulatory motifs in odorant receptor genes by analysis of promoter sequences. Genome Res. 16: 1091-1098.

Nei M, Niimura Y and Nozawa M (2008). The evolution of animal chemosensory receptor gene repertoires: roles of chance and necessity. Nat. Rev. Genet. 9: 951-963.

Svane-Knudsen V, Jorgensen KE, Hansen O, Lindgren A, et al. (1998). Cancer of the nasal cavity and paranasal sinuses: a series of 115 patients. Rhinology 36: 12-14.

Thompson LD (2009). Olfactory neuroblastoma. Head Neck Pathol. 3: 252-259.

Von Dannecker LE, Mercadante AF and Malnic B (2005). Ric-8B, an olfactory putative GTP exchange factor, amplifies signal transduction through the olfactory-specific G-protein Galphaolf. J. Neurosci. 25: 3793-3800.

Weiss GJ, Liang WS, Izatt T, Arora S, et al. (2012). Paired tumor and normal whole genome sequencing of metastatic olfactory neuroblastoma. PLoS One 7: e37029.

Zhang X, Rogers M, Tian H, Zhang X, et al. (2004). High-throughput microarray detection of olfactory receptor gene expression in the mouse. Proc. Natl. Acad. Sci. U. S. A. 101: 14168-14173.

Zhuang $\mathrm{H}$ and Matsunami H (2007). Synergism of accessory factors in functional expression of mammalian odorant receptors. J. Biol. Chem. 282: 15284-15293. 